Article

\title{
Quantitative Microstructural Analysis and X-ray Computed Tomography of Ores and Rocks-Comparison of Results
}

\author{
Oleg Popov ${ }^{1}$, Irina Talovina ${ }^{2}$, Holger Lieberwirth ${ }^{1, *}$ and Asiia Duriagina ${ }^{2}$ \\ 1 Institute of Mineral Processing Machines, TU Bergakademie Freiberg, Lampadiusstr. 4, 09599 Freiberg, \\ Germany; Oleg.Popov@iam.tu-freiberg.de \\ 2 Department of Historical and Dynamic Geology, Saint-Petersburg Mining University, 22 line, 2, \\ 199106 St-Petersburg, Russia; i.talovina@gmail.com (I.T.); gayfutdinovaam@yandex.ru (A.D.) \\ * Correspondence: holger.lieberwirth@iam.tu-freiberg.de; Tel.: +49-3731-39-2528
}

Received: 9 January 2020; Accepted: 24 January 2020; Published: 31 January 2020

\begin{abstract}
Profound knowledge of the structure and texture of rocks and ores as well as the behavior of the materials under external loads is essential to further improvements in size reduction processes, particularly in terms of liberation size. New analytical methods such as computer tomography (CT) were adopted to improve the understanding of material characteristics in rocks and ores relevant to mineral processing, particular the crushing and grinding and the modelling/simulation thereof. Results obtained on the texture and structure of identical samples of rather different rocks and ores (copper ore, granodiorite, kimberlite) are compared by $\mathrm{CT}$ with quantitative results from traditional optical microscopy obtained by quantitative microstructural analysis (QMA). While the two approaches show a good agreement of the results in many areas, the measurements with the two different methods also exhibit remarkable differences in other areas, which are discussed further. In conclusion, both methods have their specific advantages starting from sample preparation to the accuracy of information obtained concerning certain parameters of mode and fabric. While sample preparation is faster with $\mathrm{CT}$ and information on special distribution of metal minerals is more reliable, the information on mode, grain size and clustering seem to be more precise with QMA. Based on the results, it can be concluded that both methods are comparable in many areas, but in in the field of spatial distribution, they are merely complementary.
\end{abstract}

Keywords: quantitative microstructural analysis; X-ray computed tomography; selective comminution; texture; structure; mineral processing; crushing; grinding

\section{Introduction}

An increasing demand for raw materials worldwide meets a general trend towards the exploitation of lower grade new ore deposits [1-3]. Thus, ever larger quantities of ore have to be processed to produce the required amounts of concentrates. Not only rising energy costs, per processed ton of ore as well as in absolute terms, but also the accompanying $\mathrm{CO}_{2}$ emissions and the related social license to proceed are reasons for the resource industries to look for smarter solutions, particularly for the energy-intensive comminution processes.

In a study comprising numerous Australian copper mines, it was found that on average, 36 percent of the energy utilized is consumed solely by comminution processes [4]. Comminution processes for copper production alone consume about 1.223 MWh/t $\mathrm{Cu}$ [4]. Milling, in particular fine grinding in the area of liberation size, consumes thereby the largest mass specific amounts of energy. Investigation of the distribution of the valuable components in the ore, their grain size as well as the behavior of the rock and ore under certain load is therefore essential, to select the right type, magnitude and 
frequency of load and thus, respectively, the right milling machine working at appropriate operating parameters $[5,6]$.

The influence of rock and ore properties on the processing characteristics is a well-established fact [7-12]. A profound knowledge of the mineral behavior is required on all comminution steps, be it for the efficient production of preconcentrates by selective comminution on coarse particle size level [13] or the high voltage impulse comminution [14,15], or in the fine grinding. The importance of such an understanding on the microscopic level is emphasized by a number of publications and even global initiatives such as the Coalition for Energy Efficient Comminution (CEEC) [16,17]. It is also essential for the modelling and simulation of comminution processes by numerical methods, such as with the Discrete Element Method (DEM). Modelling of comminution processes with those methods provides fascinating new insights into comminution processes [18-21]. For those methods the calibration of the models for prognostic purposes poses a tremendous challenge if the differences of the mode and fabric of the various ores and rocks cannot be quantified [22-24].

The increased focus on the ore microstructure led to a number of efforts introducing new technologies into the analysis of ore microstructures. In recent years, new technologies such as the scanning electron microscope (SEM)-based Mineral Liberation Analysis (MLA) or Quantitative Evaluation of Minerals by Scanning Electron Microscopy (QEMSCAN) made their way into the mineralogist's laboratories [25,26]. More recently, also Computer Tomography (CT) was applied for mineralogical analyses [27-30]. CT is a nondestructive technique that allows for the visualization of internal structures of objects based on their different X-ray density. Originally, the method was used mainly for medical purposes, but since the 1990s it has also been used in other applications, first in petroleum geology [31-33] and later in process mineralogy [34] and process technology [27,29,30,35].

The investigation of structure and texture of ores is a pretty new but fast growing application area of CT $[36,37]$. While a number of publications support the usefulness of applying CT for analyzing mineral structures is still missing, a comparison with results acquired by traditional methods, e.g., optical microscopy. This may be caused by the missing quantitative criteria for such a comparison. The Quantitative Microstructural Analysis (QMA), a method based on optical microscopy and proven in numerous industrial applications, shall be used in this paper to compare the results obtained by the new method CT with the proven QMA. Optical microscopy has been used for decades to investigate mineral raw materials using thin or polished sections. Under polarized light, an experienced mineralogist directly identifies the various mineral varieties of the grains. Yet, optical microscopy has its limitations with regard to the image and grain size resolution, and the mineral identification, finally limited by the wave length of the light. QMA will be briefly introduced in the following chapter. A more detailed description can be found for instance in $[9,10]$.

The research presented will therefore present a comparison of structural and textural data, obtained for identical samples of three rather different materials using both methods. This allows to evaluate the capacity of CT for obtaining relevant material data of rocks and ores on microstructural level for modelling, simulation, machine and process design in crushing and milling.

\section{Methods and Materials}

\subsection{QMA—Microstructural Analysis Based on Optical Microscopy}

Descriptions of texture and structure of rocks are of great value as they can be used in the interpretation of rock formations. Microstructural descriptions are traditionally obtained by geologists using thin or polished sections for petrographic analysis. The traditional method has limitations in describing the full 3D rock structure with quantitative measures and in drawing conclusions and deriving interpretations of the microstructural information.

Quantitative Microstructural Analysis (QMA) is a collective term for a number of methods for analysing the geometry and mechanical properties of microstructural constituents. The objective is usually to investigate the relationship between the microstructure on the one hand and the properties 
of the rock or its history of origin on the other. Microstructural characteristics are often used for the classification of rocks. Methods for microstructural assessment have long been part of rock research, rock testing and production monitoring. The widening range of possible applications (petrography, mineralogy, metallography, investigation of the structure of building materials, etc.) and the development of theoretical principles (stochastic geometry, digital image processing) have led to QMA becoming a separate field of science over recent years [9,10].

The basis of the QMA of a rock sample is normally a microscope analysis of thin or polished sections. As rock-forming minerals and rock microstructures mostly have a complex three-dimensional structure, the information that can be derived from one-dimensional cut surfaces is often insufficient for the spatial quantitative characterization of the minerals and microstructures of geological materials. A three-dimensional information or the reconstruction of minerals and rock microstructures of geological materials is required. The results of mathematical-petrographic rock characterization are a precondition for predicting the relationships between rock characteristics and relevant product properties or system characteristics (e.g., wear, energy consumption) with the help of mathematical statistical modelling (e.g., multiple regression and correlation analysis) [8,38].

All the strength properties of rocks are directly dependent on the type and degree of mutual bonding of the mineral grains in the microstructure. The greater the specific surface on which the mineral grains are in contact with one another, the more mechanically competent is the rock and the more resistant to the effects of comminution processes.

The degree of grain bonding depends on grain shape and grain size. The cohesiveness of the microstructure rises as grain size decreases and specific surface correspondingly increases. With otherwise identical properties, fine-grained rocks therefore always manifest greater strength than medium and coarse-grained types. The more irregular the grain shape, the greater the grain surface area and the more intense the mutual intergrowth of adjacent individual grains [11].

The QMA usually starts with a proper extraction of a defined number of rock samples from the deposit. According to the QMA approach developed at the Institute of Mineral Processing Machines (Freiberg, Germany), model three polished sections perpendicular to each other are prepared from each rock specimen. These thin sections are evaluated with the help of a polarization microscope, assessed by means of various stereological methods (Figure 1) and classified in a library of thin sections. A mathematical model is used to characterize the rocks quantitatively, based on the calculation of relevant structural and textural characteristic data $[13,23]$.

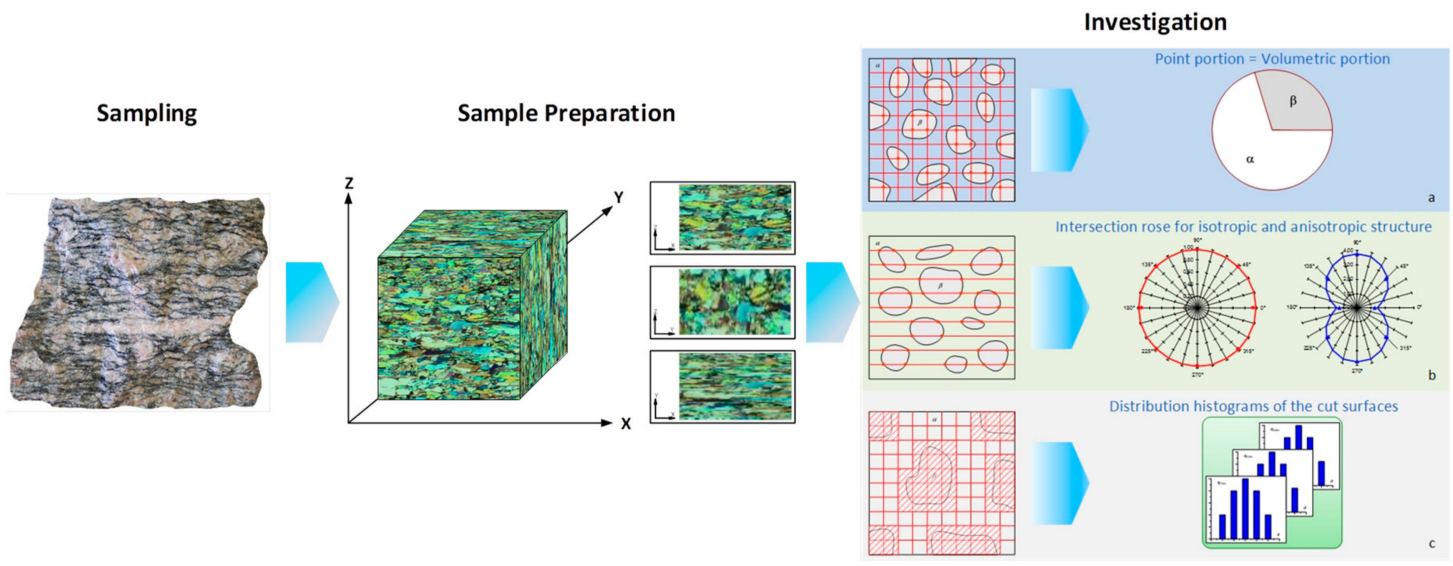

Figure 1. Process flow for QMA rock analysis.

Rock characteristics are mathematically derived in the form of characteristic values (see Table 1). These are first determined completely independently from a specific application, but can be interpreted for use with specific applications in comminution or other processes. In the following, the most important characteristic values gained by QMA (according to [8]) are explained in greater detail: 
Table 1. Rock characteristics as established by QMA under the optical microscope.

\begin{tabular}{|c|c|c|c|c|c|c|c|c|c|}
\hline \multirow{2}{*}{\multicolumn{2}{|c|}{ Raw Material }} & \multicolumn{4}{|c|}{ Rock Type: Granodiorite } & \multirow{2}{*}{\multicolumn{3}{|c|}{ Phase Related Features }} & \multirow{3}{*}{$\begin{array}{c}\begin{array}{c}\text { Raw Material } \\
\text { Features }\end{array} \\
\sum \text { Microbodies } \\
100 \\
\end{array}$} \\
\hline & & \multirow{2}{*}{\multicolumn{2}{|c|}{$\begin{array}{c}\text { Deposit: Kindisch } \\
\text { Properties }\end{array}$}} & n: Saxony & ermany & & & & \\
\hline \multicolumn{2}{|c|}{ Mode } & & & Symbol & Unit & Quartz & Feldspar & Mica & \\
\hline \multirow{5}{*}{\multicolumn{2}{|c|}{ Texture }} & Size & Mean diameter & $d_{50,3}$ & $\mathrm{~mm}$ & 0.732 & 0.928 & 0.647 & 0.810 \\
\hline & & Grain surface & Specific surface & $\mathrm{S}_{\mathrm{V}}$ & $\mathrm{mm}^{2} / \mathrm{mm}^{3}$ & 7.480 & 5.180 & 11.200 & 7.050 \\
\hline & & \multirow{2}{*}{ Shape } & Elongation & $\mathrm{E}$ & - & 1.274 & 1.330 & 1.968 & 1.425 \\
\hline & & & Flatness & $\mathrm{F}$ & - & 1.267 & 1.248 & 1.059 & 1.221 \\
\hline & & Roughness & $\begin{array}{l}\text { Rougjness } \\
\text { degree }\end{array}$ & $\mathrm{K}_{\mathrm{R}}$ & $\%$ & 30 & 13 & 38 & 23 \\
\hline \multirow{4}{*}{ Fabric } & \multirow{4}{*}{ Structure } & \multirow[t]{2}{*}{ Orientation } & $\begin{array}{c}\text { Degree of areal } \\
\text { orientation }\end{array}$ & $\mathrm{K}_{\mathrm{fl}}$ & $\%$ & 12 & 12 & 3 & 11 \\
\hline & & & $\begin{array}{l}\text { Degree of } \\
\text { isotropic } \\
\text { orientation }\end{array}$ & $\mathrm{K}_{\text {is }}$ & $\%$ & 72 & 70 & 55 & 79 \\
\hline & & Distribution & $\begin{array}{l}\text { Degree of } \\
\text { clustering }\end{array}$ & $\mathrm{C}$ & $\%$ & 36 & 41 & 13 & 34 \\
\hline & & Space filling & $\begin{array}{l}\text { Space filling } \\
\text { degree }\end{array}$ & $\varepsilon_{\mathrm{VF}}$ & $\%$ & - & - & - & 100 \\
\hline
\end{tabular}

Mode (Volume Percentage of the Mineral Phases)

The volume percentage of a mineral phase is defined as the quotient of the sum of the volume of the individual mineral grains in the sample and the sample volume. It can be most easily determined with the help of the point counting method [39].

\section{Grain Size}

The individual microbodies are polydispersed in the rock microstructure so that the size of the microbodies has to be approximated with a size distribution function. The size distribution function can be frequently approximated by a logarithmic normal distribution (LND), which is uniquely characterized by a median $\mathrm{d}_{50.3}$ and a scatter parameter $\sigma_{\ln }[8]$.

\section{Grain Shape}

The shape of a microbody corresponds to its outer appearance, which is determined by its grain shape and roughness. The grain shape is a geometric particle characteristic, i.e., a characteristic that makes allowance for all three dimensions [40]. The grain shape of a microbody can be regarded approximately as an ellipsoid with the main axes $a, b$ and $c$, where $a \geq b \geq c$. The relationship of the main axes to each other describe the grain shape of the microbody. The elongation $\mathrm{E}$ describes the "needle shape" of a particle and the flatness F of the particle its "platy shape".

Roughness

The shape of severely curved, serrated and similar complex microbodies can be analysed statistically and characterized by the roughness. This parameter can be recorded statistically in thin sections and characterized with indices. The roughness $K_{R}$ is defined as the ratio of the difference between the "real" surface area $S_{V(R)}$ and the "ideal" surface area $S_{V(I)}$ relative to the "real" surface area $\mathrm{S}_{\mathrm{V}(\mathrm{R})}$ of the individual phases. The calculation of the "ideal" surface area $\mathrm{S}_{\mathrm{V}(\mathrm{I})}$ is based on the microbody size distribution with consideration of the microbody shape and the phase volume 
percentage. The "real" surface area $S_{V(R)}$ is calculated from the three-dimensional rose of intersections. The outer shape of the microbodies largely determines the character of the microstructure [8].

Orientation

From three 2D-roses of intersections orthogonal to each other, with an approximation, the parameters of a spatial rose of intersections and their orientation angle in the space are calculated. A spatial rose of intersections of an oriented microstructure is the superposition of the roses of intersection of ideal boundary surface systems. From the parameters of the spatial rose of intersections, the orientation degrees $\left(\mathrm{K}_{\mathrm{is}}, \mathrm{K}_{\mathrm{lin}}\right.$ and $\left.\mathrm{K}_{\mathrm{fl}}\right)$ of a spatial arrangement (percentages of linear- and areal-oriented as well as nonoriented boundary surfaces) can be derived.

\section{Distribution}

Microbodies of a phase can be evenly distributed in the space, but they can also form clusters in which the microbodies of a phase share boundary surfaces. The degree of clustering $C$ is defined as the quotient of the sum of the boundary surfaces between the grains of the same mineral group and the total boundary surface of this mineral group. The degree of clustering can be calculated with the help of linear analysis [8].

\section{Space Filling}

Rocks are practically never completely compact, i.e., the aggregate space is not completely filled by solid constituents, but there are cavities (pores) between them, which normally contain gas (e.g., air) and/or aqueous solutions. The space filling degree $\varepsilon_{V F}$ can vary within wide boundaries for different rocks. The size, distribution and type of pores also show great differences. To assess many properties of the rocks, it is necessary to examine the character of the space filling more closely.

\subsection{X-ray Computed Tomography (CT)}

$\mathrm{CT}$ evolved as an effective supplement in the complex studies of petrophysical properties of rocks. It includes the definition of porosity, fracturing, cavities and their distribution by diameter, volume, and sphericity degree. Moreover, microtomography is a useful tool for the measurement of mineral phases with equal X-ray density throughout the whole sample. The main advantages of the method include also the wide visualization potentials with comparably low measurement time.

Principles of CT are described in detail in numerous papers [27,29,35]. The method consists in essence in weakening the power of the $\mathrm{X}$-ray beam when passing through a certain volume of the material. During scanning in X-ray beam, the sample is rotated around a vertical axis by $180^{\circ}$ with a certain step. The result of the scan is fixed by the shadow projection (using $\mathrm{Al}$ or Brass filters behind the sample and before the detector). Shadow projections are graphic files where each pixel contains information about the amount of $X$-ray absorption by the object at a given point. This value is expressed in 256 grey color shades (the darker, the higher the absorption). The processing of the obtained results consists in the mathematical transformation of the shadow vertical projections into a series of horizontal sections of the object using special software CTAn (e.g., Version 1.95, Bruker, Kontich, Belgium). After reconstruction, the most important step of the analysis is the volumetric visualization.

During the binarization of images, e.g., with the help of the CTVox software (Version 2.14, Bruker, Kontich, Belgium) it is possible to create three-dimensional images of the sample for further visual studies and morphometric analysis (Figure 2).

In this paper, the CT studies of typical ore/rock samples were carried out by using a microtomograph "SkyScan-1172" (Bruker, Kontich, Belgium) with resolutions from 19.58 to $32.32 \mu \mathrm{m}$, equipped with the certified programs Skyscan1172 $\mu \mathrm{CT}$, NRecon, DataViewer, CTVox, CTAn, CTVol, SkyScan_MTS, Gidropora. The shooting parameter set for scanning the samples is shown in Table 2. 
a) Scanning

b) Visualisation

c) Reconstruction

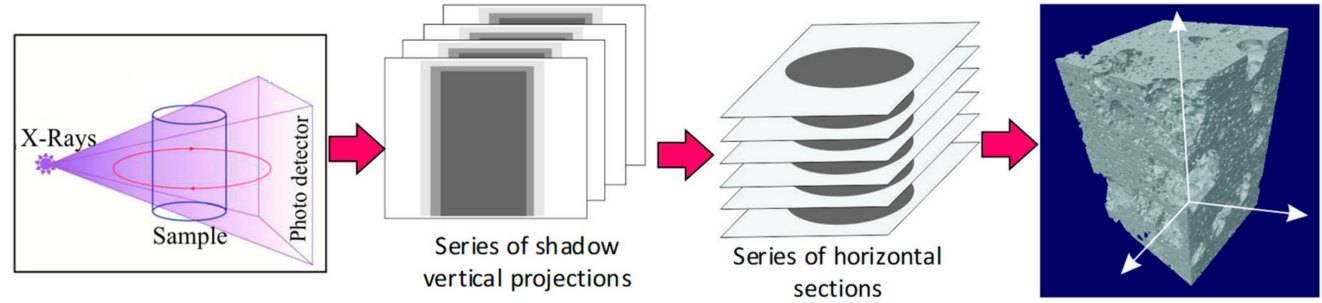

Figure 2. Basic principles of CT: (a) scanning of the sample in X-ray beam, (b) mathematical transformation of the shadow vertical projections into a series of horizontal sections of the object, (c) creation of three-dimensional images of the sample.

Table 2. The shooting parameters set for scanning the samples.

\begin{tabular}{ccccc}
\hline Parameters & Unit & Copper Sandstone & Granodiorite & Kimberlite \\
\hline Accelerating voltage & $\mathrm{kV}$ & 100 & 125 & 130 \\
Current rate & $\mathrm{mA}$ & 80 & 61 & 61 \\
Resolution & $\mu \mathrm{m}$ & 19.58 & 32.32 & 19.58 \\
Filter & $\mathrm{mm}$ & $\mathrm{Al} 0.1$ & Brass 0.25 & Brass 0.25 \\
\hline Rotation step & grade & & 0.100 & \\
\hline
\end{tabular}

\subsection{Sample Materials}

A rock can be described based on the content of its mineral components and its fabric (Figure 3). It consists of the individual mineral phases, but often also contains defects (e.g., pores, cracks), which form the continuous phases (gas or liquid phase) and glasses as well as cryptocrystalline masses which are combined to a nondifferentiated phase. Each single constituent of a phase-also termed microbody or grain-takes up a certain volume that is defined by boundary surfaces.

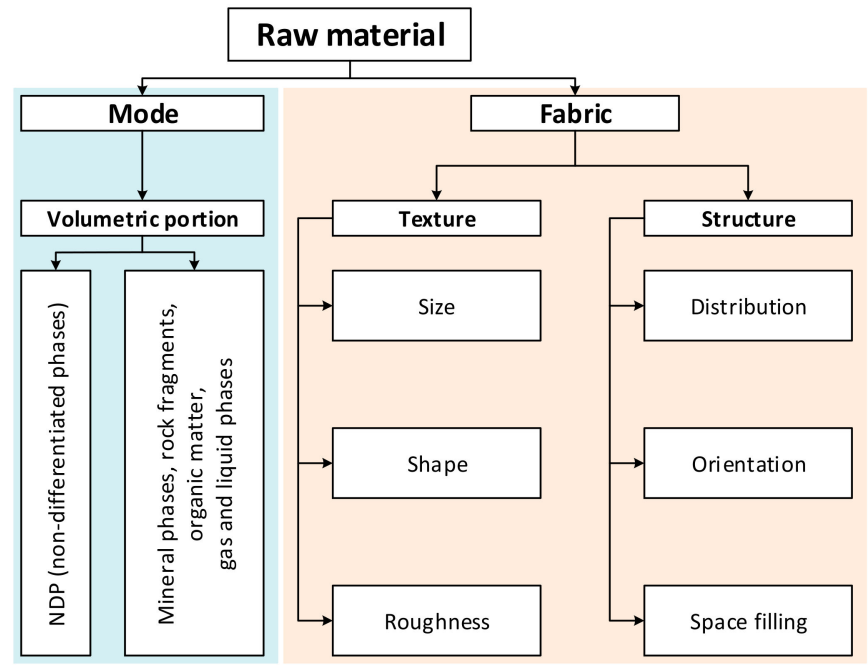

Figure 3. Characterization of raw materials.

To introduce the characteristics of the rock fabric in technology assessment, the texture must be expressed in figures. Based on the application of stereological methods, the rock is quantitatively described by means of its

- $\quad$ mode (volume percentage of the mineral phases),

- characteristic values of the texture (e.g., grain size and shape, roughness),

- $\quad$ characteristic values of the structure (e.g., orientation, distribution and space filling). 
The term "rock fabric", comprising texture and structure, can be understood as the quantity of all geometric data of a piece of rock. The characteristics of the rock fabric, quantified with the help of QMA methods, are based on the formal characterization of the rocks by geologists in order to facilitate understanding between geologists and engineers with their respective terminology.

The texture of a rock is the term used to describe the nature of its composition by individual components. It is dictated by the form of the individual mineral components and their mutual geometric relationships. Accordingly, the grain shapes and the grain sizes of the mineral components are essential elements of the rock texture.

The structure of a rock depends on the spatial arrangement of its components. In this case, the components are less the individual grains and far more complexes of the same minerals or other identical structural elements. In this context, the orientation of the components as the directional texture, the distribution of the same as the distribution texture and relative density (compact and porous rocks) are taken into consideration. Rocks with strata of varying mineral composition therefore have an inhomogeneous distribution texture; lava with gas bubbles is characterized by their incomplete space filling.

For the comparison of QMA and CT three different samples were investigated. Their characteristics, described by mode and fabric, but inherently representing also mechanical properties relevant for comminution, ore content vary widely, to cover a range of materials from metal and non-metal mining as well as the aggregate industry. The need to crush and, to a certain extent at least, grind the material to produce a sellable product is the bracket that connects those industries. The investigated samples contain:

- copper ore (green sandstone ore) from Legnica (Poland),

- granodiorite from Kindisch (Saxony, Germany),

- kimberlite from Letseng (Lesotho).

\section{Results}

In the following, the results of the QMA and the $\mathrm{CT}$ analyses of the three different sample materials are presented.

\subsection{Copper Ore}

\subsubsection{QMA Results (Copper Ore)}

Mode

Copper ore from Legnica consists of $17 \%$ copper minerals in a quartz (64\%) and calcite matrix (19\%) (see Figure 4).

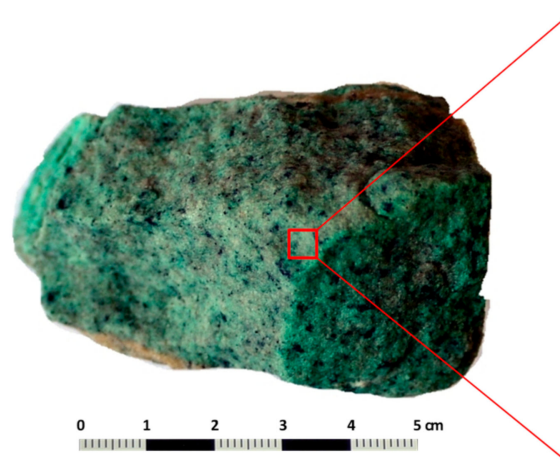

a)

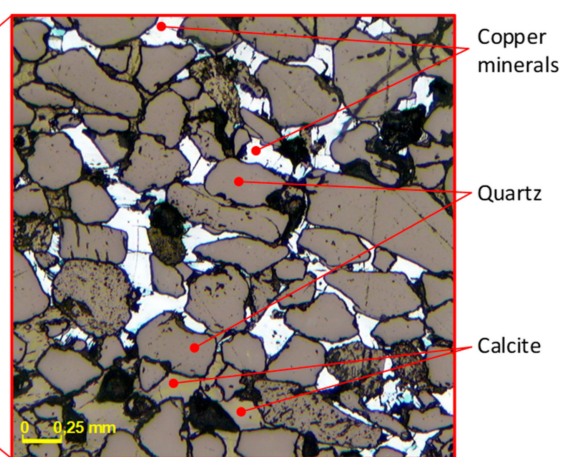

b)

Figure 4. Copper ore (green sandstone ore): (a) hand specimen, (b) microphotograph under reflected light. 


\section{Grain Size}

The quartz shows a mean grain size of $265 \mu \mathrm{m}$ and the copper minerals with $277 \mu \mathrm{m}$ are of similar size. The standard deviation $\sigma_{\ln }$ of the diameter distribution of the copper minerals shows a scatter parameter of 0.504 . Figure 5 shows the grain size distribution of both minerals as identified by QMA.

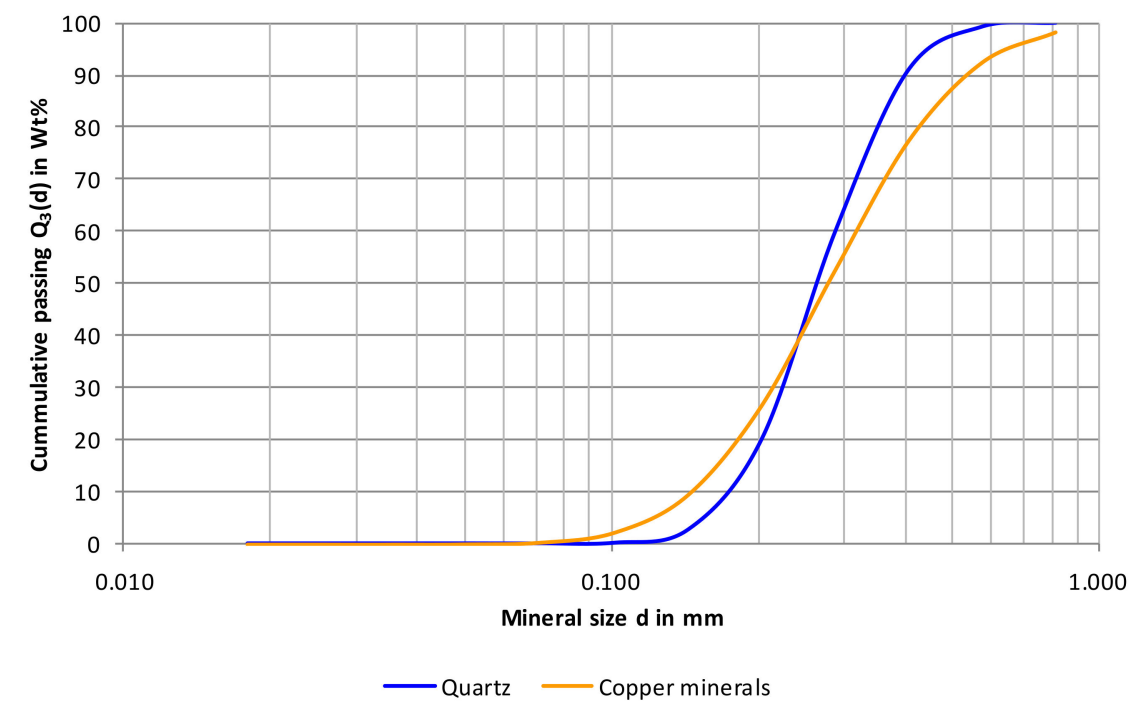

Figure 5. Mineral grain size distribution of the copper ore according to QMA.

\section{Grain Shape}

The shape of the copper minerals of the copper ore is predominantly platy-like. This is confirmed by the values for their elongation $E$ and flatness $F(E=1.224 ; F=1.156)$. In comparison, the shape of the quartz is predominantly needle-like. This is confirmed by respective elongation and flatness values $(\mathrm{E}=1.458 ; \mathrm{F}=1.162)$.

\section{Roughness}

The roughness $\mathrm{K}_{\mathrm{R}}$ of the copper minerals is around $62 \%$ and is therefore in a very high range compared to minerals of other rock fabrics.

\section{Specific Surface Area}

The specific surface area $S_{V}$ of the copper minerals is in the medium range and is around 53 $\mathrm{mm}^{2} / \mathrm{mm}^{3}$ per mineral grain. The specific surface area and the roughness characterize the "intergrowth" of the minerals with each other. This intergrowth is an important information since it allows to draw conclusions on the breakage behaviour of a material, the specific energy consumption, wear of comminution machine parts etc.

\section{Degree of Clustering}

The degree of clustering $C$ shows whether a mineral grain forms an agglomeration in the rock with another mineral grain of the same type. The quartz shows a $6 \%$ cluster formation, that is, $6 \%$ of all quartz grain surfaces lie next to another quartz grain surface.

\section{Space Filling}

The very good space filling means that moisture can only adhere to the surface of particles, as there are no pores in the ore sample. 


\subsubsection{CT Results (Copper Ore)}

Mode

Copper ore consists, according to CT, of $5.2 \%$ of ore minerals, quartz grains $(53.1 \%)$ and a matrix of crystallized calcite (40.9\%). The distribution of copper minerals in the entire rock volume is shown in Figure 6. It can be seen that it is possible to clearly distinguish dense copper-containing minerals from quartz and calcite on the tomogram, whereas the latter two minerals are quite difficult to distinguish from each other, because of their close X-ray density.
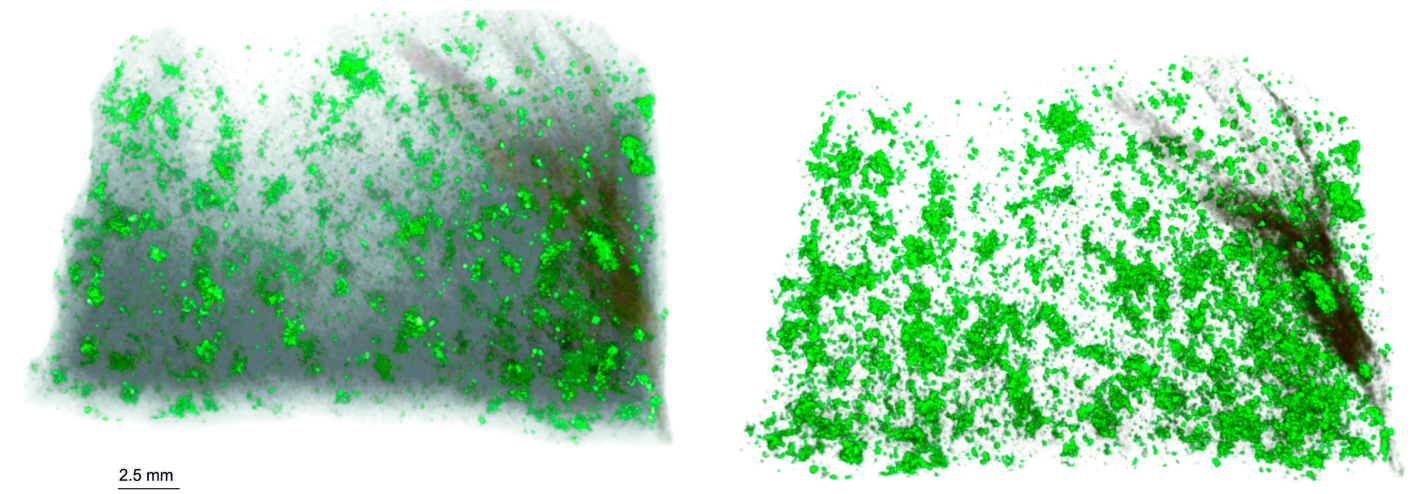

Figure 6. The distribution of copper minerals (green) in the quartz-calcite matrix (gray) in sandstone.

\section{Grain Size}

Using the CTVox and CTan programs, it is possible to analyse in detail not only the sizes of the grains composing the rock, but also their interrelations, which is especially important for the purposes of process mineralogy. Copper minerals are fairly evenly distributed throughout the rock volume, sometimes forming individual grains with an average size of $70 \mu \mathrm{m}$ and fine-grain aggregates $260 \mu \mathrm{m}$ in size (Figure 7a,b), sometimes up to 2.0-4.5 mm (Figure 7c).

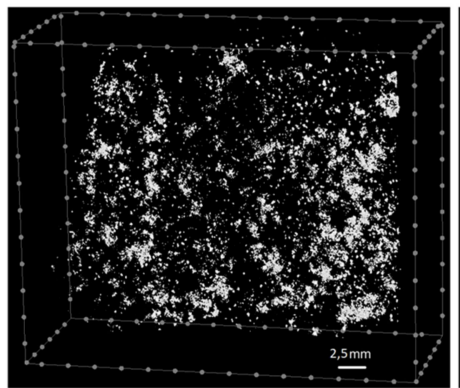

a)

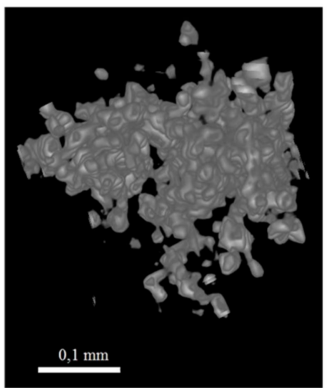

b)

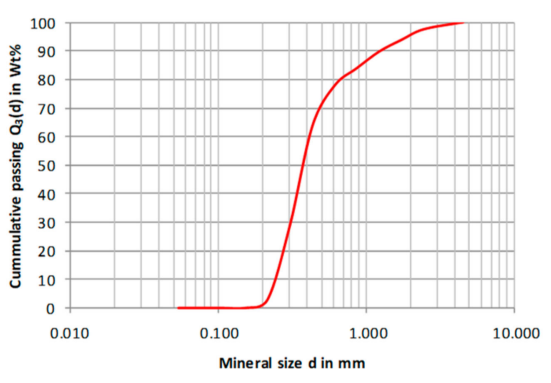

c)

Figure 7. (a,b) Aggregates of copper minerals in the volume of sandstone and (c) aggregate distribution according to the maximum diameter.

\section{Grain Shape}

Copper minerals have a quite isometric shape, the coefficient of sphericity, calculated as the ratio of the short to the long axis, is 0.78 (when the shape of the grain approaches isometric, this coefficient reaches 1, Figure 8a). 


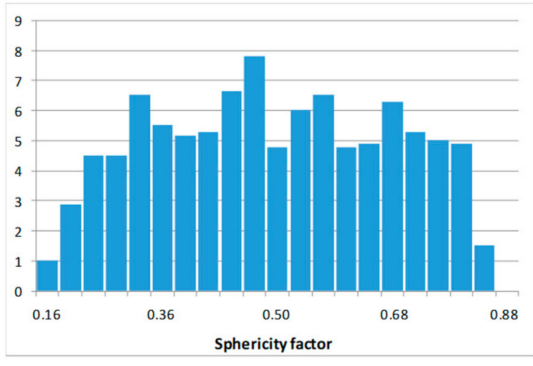

a)

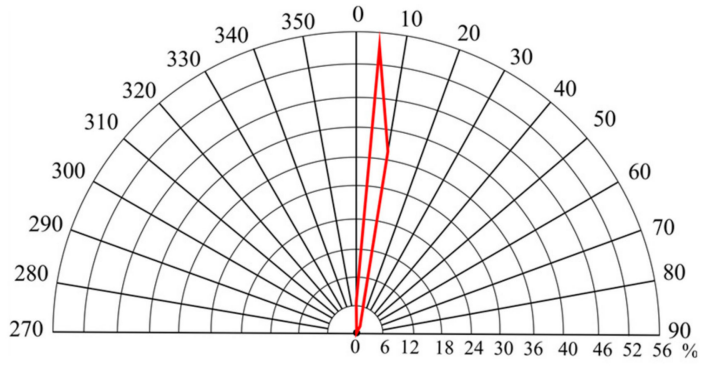

b)

Figure 8. (a) Distribution of aggregates of copper minerals according to the sphericity coefficient and (b) the orientation of the longest axis, grade

\section{Roughness}

Specific surface of copper minerals, calculated as the ratio of the total surface of minerals to their volume and representing the degree of tortuosity of the boundaries (roughness), is equal to $31.86 \mathrm{~mm}^{2} / \mathrm{mm}^{3}$.

\section{Orientation}

The orientation of copper grains and aggregates is also marked, expressed quantitatively as the deviation of the longest axis of grains from the vertical in grades (Figure $8 b$ ).

\section{Porosity}

One of the most important characteristics of rocks for comminution, linking the strength of the rock with a defect in its structure, is porosity. It determines the interpretation of the strength properties and behavior of the rock during comminution [30]. The total porosity of the sandstone sample is $1.4 \%$, the open porosity is $0.68 \%$. The pore connectivity is low. In general, the pores of the subcapillary size are less than $0.2 \mu \mathrm{m}$, the predominant pore size is $25-50 \mu \mathrm{m}$, but there are also single pores with a diameter of more than $100 \mu \mathrm{m}$. The pore sphericity factor is 0.62 . The void density, calculated as the ratio of the number of pores per unit volume of rock, is $9.10 \mathrm{~mm}^{-3}$.

\subsection{Granodiorite}

\subsubsection{QMA Results (Granodiorite)}

Mode

Granodiorite from Kindisch consists of 34\% quartz, 48\% feldspar and 18\% mica (see Figure 9).

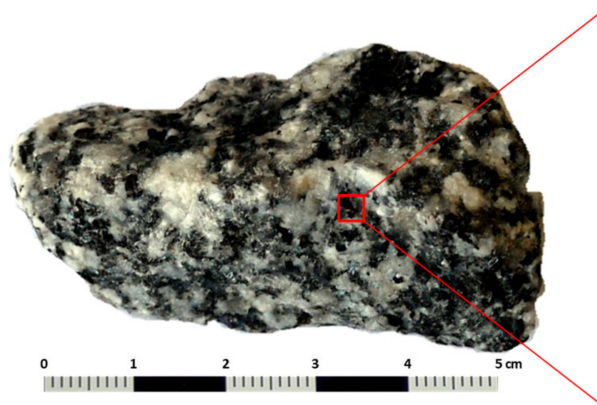

a)

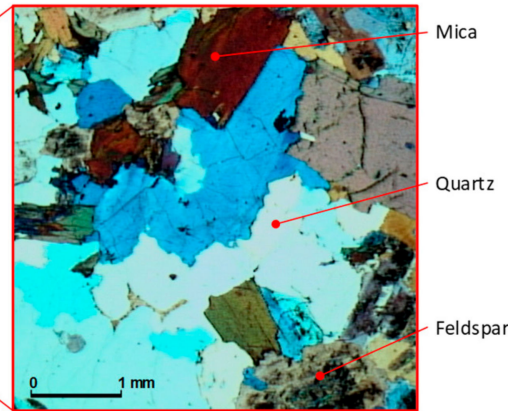

b)

Figure 9. Granodiorite (a) hand specimen, (b) microphotograph under transmitted light with lambda/4 plate. 
The effects of these minerals on the mechanical characteristics of the rock and, hence, its comminution behaviour and abrasivity are quite different. The mineral quartz is a positive development in terms of strength, weathering and temperature resistance. Due to its high Mohs hardness, it increases the abrasivity of a rock in comminution. The feldspars consist of polysynthetic twinned plagioclase and alkali feldspars. The most singular property of mica is its physical structure. As a sheet mineral it can be split into strong, flexible films having good high-temperature resistance. Its mechanical properties, however, vary substantially depending on the direction of loads relative to the direction of the films. While the grain strength is rather high with compression loads rectangular to the film planes the material strength with regard to compression loads acting in the planes is usually comparably low.

\section{Grain Size}

The mean grain size of all minerals is rather different. The quartz shows a mean grain size of $732 \mu \mathrm{m}$, the feldspar $928 \mu \mathrm{m}$, the mica $647 \mu \mathrm{m}$. The overall mean grain size of the rock is $810 \mu \mathrm{m}$ (Figure 10). The diameter distribution of the mica shows a scatter parameter of 0.414 .

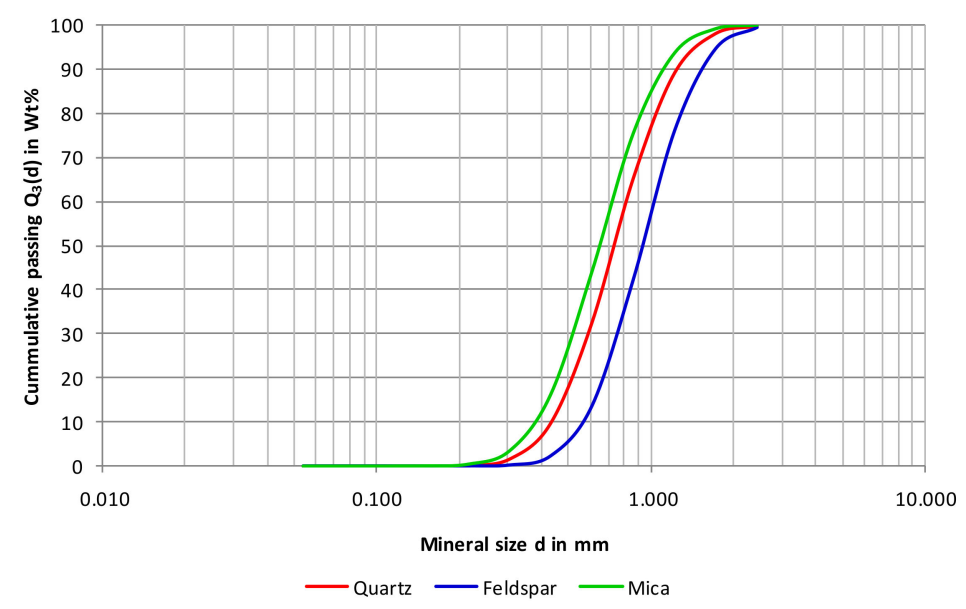

Figure 10. Mineral grain size distribution of granodiorite.

\section{Grain Shape}

The grain shape of the mica looks like needle-shaped. This is confirmed by the values of their elongation and flatness $(\mathrm{E}=1.968 ; \mathrm{F}=1.059)$. In comparison, the overall grain shape of all minerals of granodiorite is mainly needle-platy, with elongation and flatness values $(\mathrm{E}=1.425 ; \mathrm{F}=1.221)$.

\section{Roughness}

The roughness $K_{R}$ of the mica minerals is approximately $38 \%$ and is therefore in very high range compared to minerals of other rock fabrics.

\section{Specific Surface Area}

The specific surface area $S_{V}$ of the mica minerals is approximately $11 \mathrm{~mm}^{2} / \mathrm{mm}^{3}$ per mineral grain.

\section{Degree of Clustering}

The mica shows a $13 \%$ cluster formation, which means $13 \%$ of all quartz grain surfaces lie next to another mica grain surface.

\section{Isotropic Orientation}

The isotropic orientation degree $\mathrm{K}_{\mathrm{is}}$ is about $79 \%$. These values give an indication that the production of cubic products is only possible by increased machine expenditures (e.g., multi-stage 
comminution and preferably by impact loading) and matched operating mode of the processing plant (e.g., high stress intensity).

\subsubsection{CT Results (Granodiorite)}

Mode

The granodiorite contains $89.3 \%$ of quartz-feldspar mass and $7.7 \%$ of mica according to the $\mathrm{CT}$ results. Mica is fairly evenly distributed throughout the rock volume, forming slightly oriented flattened grains of $0.594 \mathrm{~mm}$ in size (Figure 11a). There are also individual aggregates of $1.8-3.0 \mathrm{~mm}$ (Figure 11b).

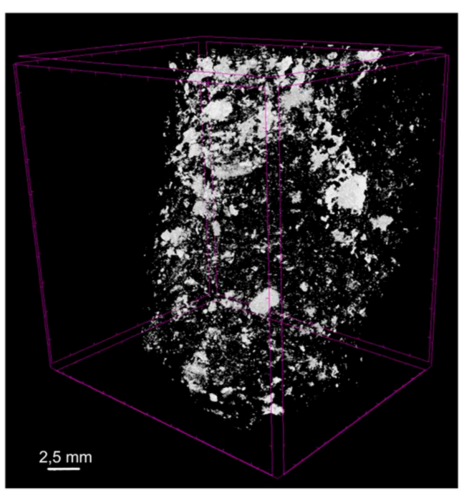

a)

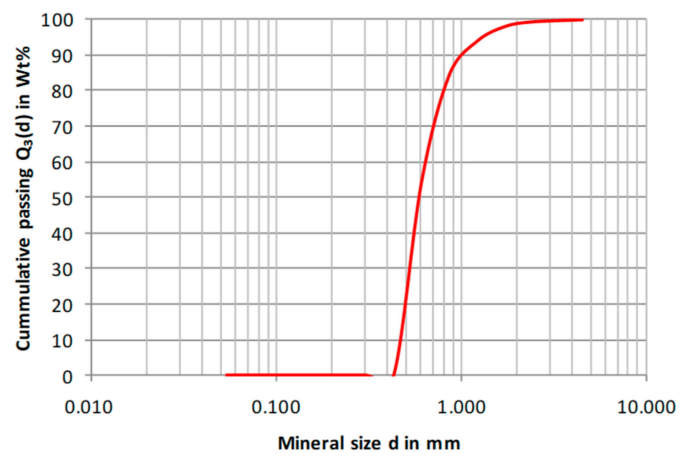

b)

Figure 11. (a) Mica in the volume of granodiorite and (b) their distribution according to the maximum diameter.

\section{Grain Shape}

Mica grains have a flattened morphology $\left(\mathrm{K}_{\mathrm{sph}}=0.48\right)($ Figure 12a).

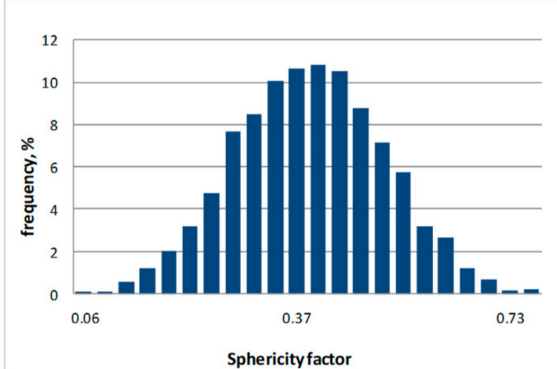

a)

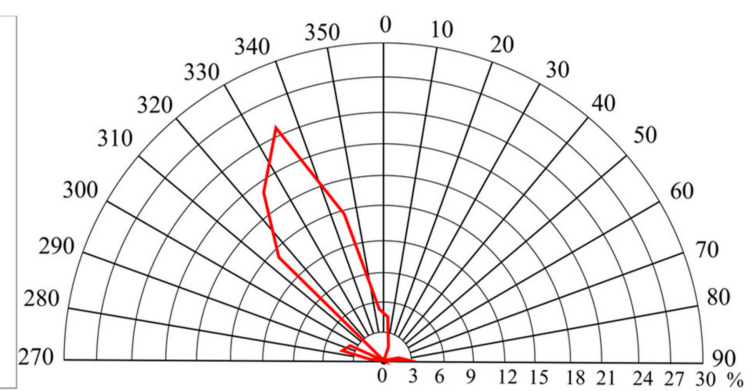

b)

Figure 12. (a) Distribution of mica according to the sphericity factor and (b) the orientation of the longest axis.

Specific Surface Area

The specific surface area, i.e., the degree of tortuosity of the boundaries is $20.2 \mathrm{~mm}^{2} / \mathrm{mm}^{3}$.

Isotropic Orientation

There is also a strong orientation of the mica grains (Figure 12b).

Porosity

The total porosity of the granodiorite sample is $3.05 \%$, the opened porosity is $0.91 \%$. Basically, pores are of subcapillary and capillary size $(15-40 \mu \mathrm{m})$, there are single pores with a diameter of more 
than $100 \mu \mathrm{m}$. The predominant shape of pores is close to spherical (sphericity factor is 0.80 ). The void density is $2.06 \mathrm{~mm}^{-3}$.

\subsection{Kimberlite}

\subsubsection{QMA Results (Kimberlite)}

Mode

Kimberlite from Letseng consists of so-called phenocrysts (21\% olivine, $20 \%$ pyroxene) and nondifferentiable phase (59\%). This nondifferentiable phase (NDP) consists mostly of an irregular mixture of serpentine, chlorite, pyroxene, olivine and ore minerals (Figure 13).

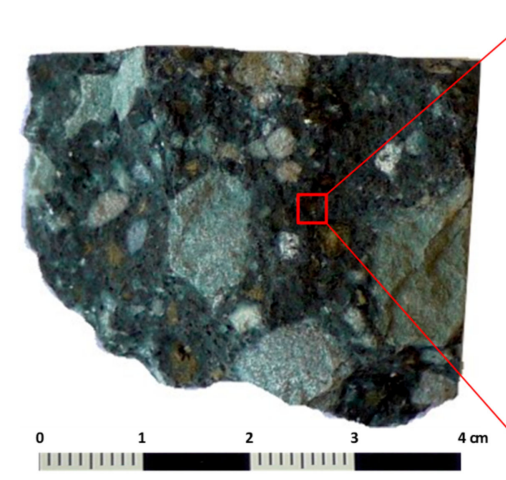

a)

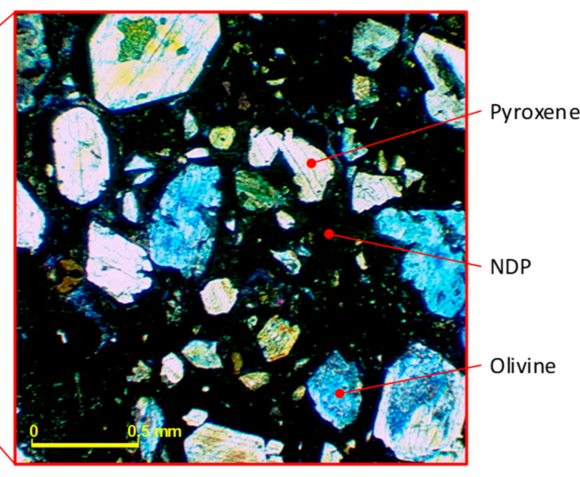

b)

Figure 13. Kimberlite: (a) hand specimen, (b) microphotograph under transmitted light with lambda/4 plate.

\section{Grain Size}

The grain size differs between the phenocrysts. The olivine shows a mean grain size of $679 \mu \mathrm{m}$, the pyroxene a size of $324 \mu \mathrm{m}$, the phenocrysts having a mean grain size of $503 \mu \mathrm{m}$ overall (Figure 14). The diameter distribution of the phenocrysts shows a scatter parameter of 0.334 .

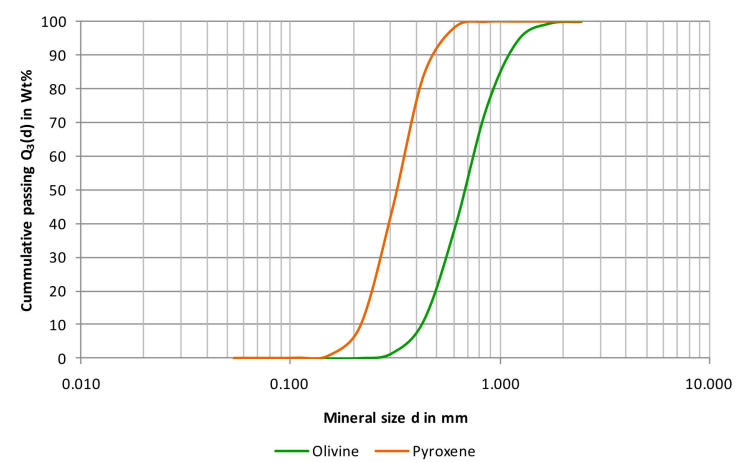

Figure 14. Mineral grain size distribution of phenocrysts (olivine and pyroxene).

\section{Grain Shape}

The shape of the phenocrysts is predominantly cubic, confirmed by the values for their elongation and flatness $(\mathrm{E}=1.238 ; \mathrm{F}=1.067)$. 


\subsubsection{CT Results (Kimberlite)}

Mode

Kimberlite consists of a fine-grained carbonate-serpentine mass (26.4\%) with olivine inclusions (together $32.7 \%)$, pyroxene (33.5\%) and accessory minerals $(7.4 \%)$.

\section{Grain Shape}

Olivine and pyroxene grains are often of irregular shape, the sphericity coefficient for olivine is 0.23 , and pyroxene is 0.48 (Figure 15a).

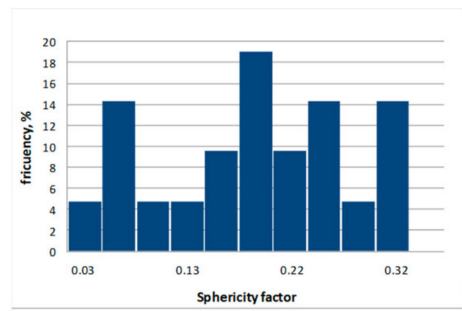

a)

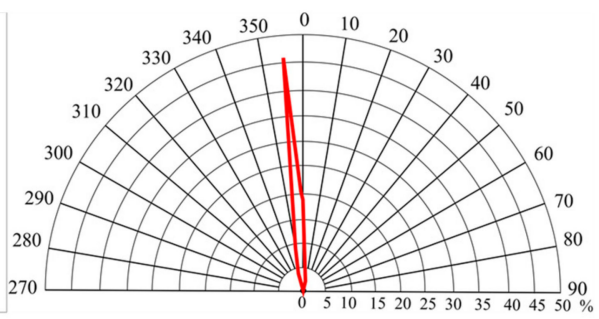

b)

Figure 15. (a) Distribution of olivine grains according to the sphericity coefficient and (b) the orientation of the longest axis in grade

\section{Specific Surface}

The specific surface for both olivine and pyroxene is large (40.17 and $56.10 \mathrm{~mm}^{2} / \mathrm{mm}^{3}$ respectively), which again indicates a complex morphology of grains.

\section{Orientation}

Olivine grains are slightly orientated in the rock volume (Figure 15b).

\section{Clustering}

The pyroxene and olivine grains are distributed in the rock very unevenly, they form separate clusters of 1.161-1.595 $\mathrm{mm}$ in size respectively (Figure 16a), and single aggregates up to $15 \mathrm{~mm}$ in size as well (Figure 16b).

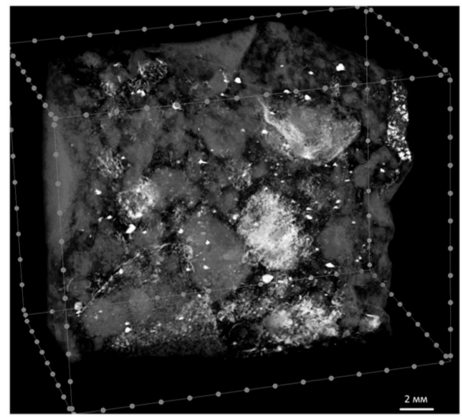

a)

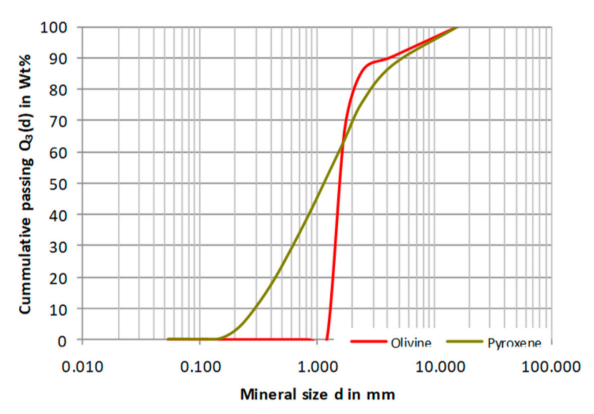

b)

Figure 16. (a) Olivine and pyroxene grains in the volume of kimberlite and (b) their distribution according to the maximum diameter.

Porosity

A sample of kimberlite is characterized by a minimal porosity: the total porosity is $0.13 \%$ and the opened porosity is $0.02 \%$. In general, the pores are of $15-50 \mu \mathrm{m}$ in size and have irregular shape (sphericity factor is 0.66 ). The void density is $12.81 \mathrm{~mm}^{-3}$. 


\section{Discussion}

Analysis of the data obtained in the study of three different rock types using CT and QMA allows to reveal interesting textural and structural features. Thus, for example, both methods give sufficiently close measurements for such a parameter like the sizes of grains and mineral aggregates, especially if they sharply differ from the surrounding minerals in X-ray density. In this regard, the maximum correspondence of the data $(0.647$ and $0.594 \mathrm{~mm})$ is observed for mica grains enclosed in a quartz-feldspar matrix of granodiorite, which is particularly well observed in Figure 17.

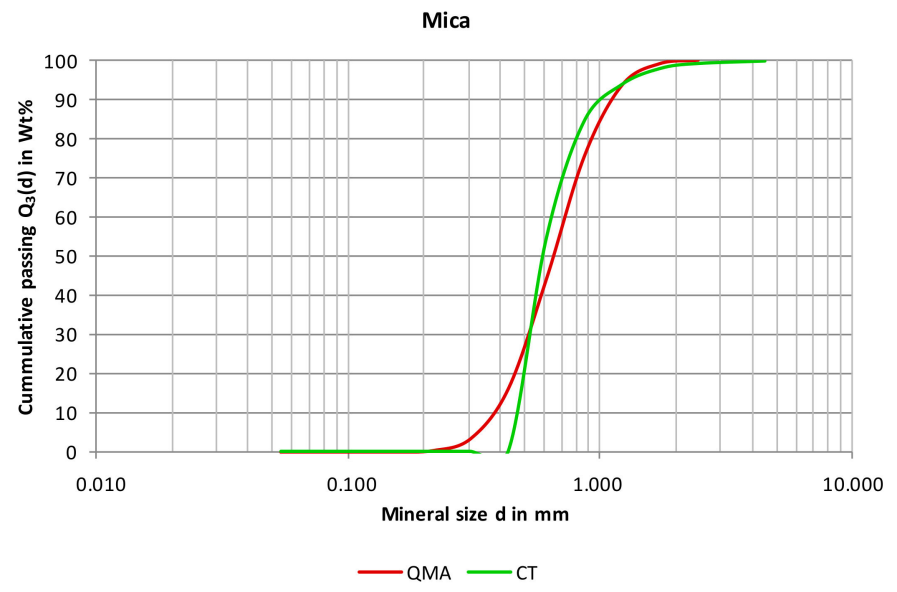

Figure 17. Grain size distributions of mica in granodiorite.

Thus, the CT method was proven to be an efficient tool to analyse materials with high X-ray density such as ore minerals (native elements, sulphides and metal oxides) in a matrix consisting of low X-ray density materials such as silicates (quartz, feldspar, olivine, pyroxenes, amphiboles, etc.) or carbonate matrix. The CT often analyzes not individual grains of minerals, but their aggregates. So, there may be slightly overestimated mean diameters of grains and their aggregates, which occurred with copper minerals in copper ore (see Figure 18). The calculated sizes of these minerals according to the CT data exceed the QMA data (0.381 and $0.277 \mathrm{~mm}$, respectively), since one grain is taken as the aggregate of grains of copper minerals.

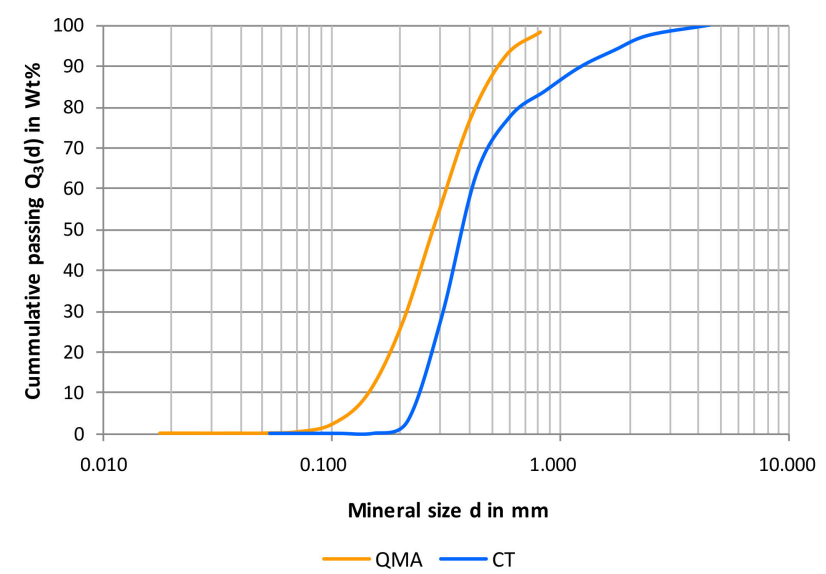

Figure 18. Grain size distributions of copper minerals in copper ore.

Similar distortions can occur for other morphometric parameters, such as, for example, the specific surface area of grains (see Table 3). In such cases, tomographic studies must be accompanied by additional petrographic and electron microscopic studies, but in this case, one of the main advantage of CT-the speed of the method-is lost. 
Table 3. Comparison of the specific surface of minerals obtained with QMA and CT.

\begin{tabular}{|c|c|c|c|c|c|c|}
\hline \multirow[t]{2}{*}{ Parameter } & \multicolumn{2}{|c|}{$\begin{array}{c}\text { Copper Ore } \\
\text { (Copper Minerals) }\end{array}$} & \multicolumn{2}{|c|}{$\begin{array}{l}\text { Granodiorite } \\
\text { (Mica) }\end{array}$} & \multicolumn{2}{|c|}{$\begin{array}{l}\text { Kimberlite } \\
\text { (Olivine) }\end{array}$} \\
\hline & QMA & CT & QMA & CT & QMA & CT \\
\hline $\begin{array}{l}\text { Specific surface } \\
\mathrm{S}_{\mathrm{V}} \mathrm{mm}^{2} / \mathrm{mm}^{3}\end{array}$ & 52.84 & 31.86 & 11.20 & 20.20 & 6.23 & 40.17 \\
\hline
\end{tabular}

Some differences in estimated parameters can also be explained by the peculiarity of sample preparation for CT and QMA: by the CT method the total volume of a sample is scanned while for QMA three orthogonally oriented sections are investigated. Accordingly, the sample volume is different in both cases. For example, several large phenocrysts of olivine in the very heterogeneous kimberlite sample influenced significantly the values of the average morphometric parameters of the whole sample (see Figure 19).

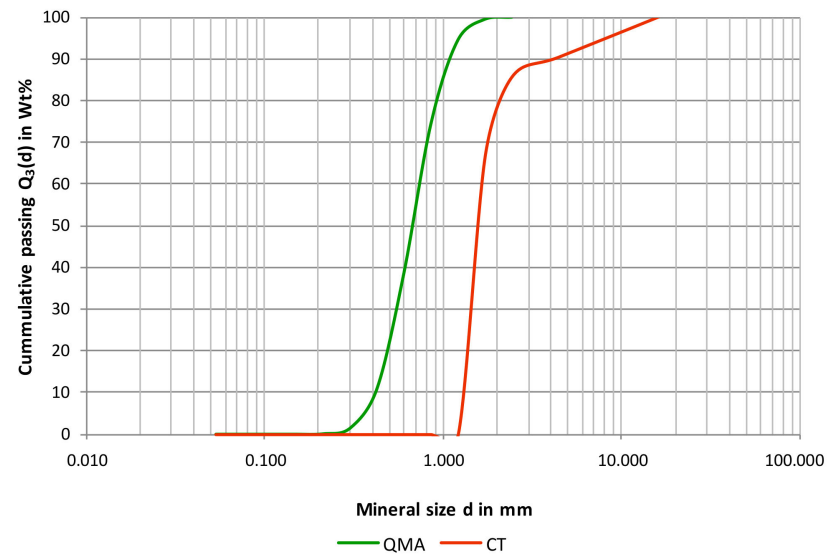

Figure 19. Grain size distributions of olivine in kimberlite.

\section{Conclusions}

In the paper, a comparative analysis of textural-structural rock characteristic using QMA and CT methods is carried out. The undoubted advantage of the CT method is the possibility of 2D and 3D data visualization with the help of specialized programs such as CTVox and CTan, which help to analyse not only the grain and agglomerate sizes, but also their distribution in the total rock volume and relationships with each other. Although, possibilities of $\mathrm{CT}$ are not enough for measuring separate grains while their similar density. In these cases, the QMA results are much more representative.

The sample preparation for each method differs as well. Thus, CT is a non-destructive method and it is possible to analyse hand specimens. Whereas QMA requires more difficult and lengthy preparations (three orthogonally orientated thin sections or polished sections should be prepared).

So, it can be concluded that it is possible to use $\mathrm{CT}$ as a quick simple nondestructive method, as well as for more serious and difficult measurements, it is better to use QMA method. The analysis of the obtained data indicates a quite good repeatability of measurements, and consequently, the possibility of using the CT method in addition to other methods such as QMA for the purpose of studying the behaviour of rocks and ores during their beneficiation, in particular for the better understanding the important process of comminution.

Author Contributions: Conceptualization, H.L.; methodology, O.P. and I.T.; software, A.D.; validation, A.D.; O.P.; formal analysis, I.T.; H.L.; investigation, A.D.; O.P.; data curation, A.D.; O.P.; writing-original draft preparation, A.D.; O.P.; writing-review and editing, I.T.; H.L.; visualization, A.D.; O.P.; supervision, I.T.; H.L.; project administration, I.T.; H.L.; funding acquisition, I.T.; H.L. All authors have read and agreed to the published version of the manuscript. 
Funding: The CT Study was performed as part of the Joint German-Russian Project No 20-55-12002 of the Russian Foundation for Basic Research.

Conflicts of Interest: The authors declare no conflict of interest.

\section{References}

1. Bringezu, S.; Ramaswami, A.; Schandl, H.; O’Brien, M.; Pelton, R. Assessing Global Resource Use: A Systems Approach to Resource Efficiency and Pollution Reduction. 2017. Available online: https://wedocs.unep.org/ bitstream/handle/20.500.11822/27432/resource_use.pdf?sequence=1 (accessed on 25 January 2020).

2. Schodde, R. Role of Technology and Innovation for Identifying and Growing Economic Resources. In Proceedings of the 12th Biennial Exploration Managers Conference, Hunter Valley, Australia, 26-29 July 2019.

3. Steinbach, V. E-mobility-The Global Race for High-Tech Metals. In Proceedings of the 100 years IEC, Scientific Colloquium - Solutions for the Carbon Challenge, Berlin, Germany, 10-12 October 2019.

4. Ballantyne, G.R.; Powell, M.S. Benchmarking comminution energy consumption for the processing of copper and gold ores. Miner. Eng. 2019, 65, 109-114. [CrossRef]

5. Hesse, M. Selektive Zerkleinerung von Erzen und Industriemineralen bei Prallbeanspruchung; TU Bergakademie Freiberg: Freiberg, Germany, 2017. (In German)

6. Li, X.F.; Li, X.; Li, H.B.; Zhang, Q.B.; Zhao, J. Dynamic tensile behaviours of heterogeneous rocks: The grain scale fracturing characteristics on strength and fragmentation. Int. J. Impact Eng. 2018, 118, 98-118. [CrossRef]

7. Aleksandrova, T.N.; Nikolaeva, N.V.; Lvov, V.V.; Romashev, A.O. Ore processing efficiency improvements for precious metals based on process simulations. Obogashchenie Rud 2019, 2, 8-13. [CrossRef]

8. Popov, O. Beitrag zur Mathematisch-Petrographischen Gefügecharakterisierung für die Beurteilung der Festgesteine Hinsichtlich Ihrer Aufbereitung und Ihrer Produkteigenschaften; TU Bergakademie Freiberg: Freiberg, Germany, 2007. (In German)

9. Popov, O.; Lieberwirth, H.; Folgner, T. Quantitative Charakterisierung der Festgesteine zur Prognostizierung des Gesteinseinflusses auf relevante Produkteigenschaften und Systemkenngrößen. Teil 1: Anwendung der quantitativen Gefügeanalyse. AT Miner. Process. 2014, 07-08, 76-88.

10. Popov, O.; Lieberwirth, H.; Folgner, T. Quantitative Charakterisierung der Festgesteine zur Prognostizierung des Gesteinseinflusses auf relevante Produkteigenschaften und Systemkenngrößen. Teil 2: Ausgewählte Beispiele. AT Miner. Process. 2014, 10, 54-63.

11. Schreiber, S. Beitrag zur Quantitativen Gesteinscharakterisierung zur Beurteilung von Gesteinen hinsichtlich Ihrer Festigkeiten; TU Bergakademie Freiberg: Freiberg, Germany, 2018. (In Germany)

12. Tromans, D. Crack Propagation in Brittle Materials: Relevance to Minerals Comminution. Int. J. Recent Res. Appl. Stud. 2012, 11, 406-427.

13. Hesse, M.; Popov, O.; Lieberwirth, H. Increasing efficiency by selective comminution. Miner. Eng. 2017, 103-104, 112-126. [CrossRef]

14. Mezzetti, M.; Popov, O.; Lieberwirth, H.; Anders, E.; Hoske, P. Electro Impulse Technology for Processing Complex Ores. In Proceedings of the ESCC European Symposium on Comminution and Classification, Izmir, Turkey, 11-14 September 2017.

15. Zuo, W.; Shi, F.; Manlapig, E. Modelling of high voltage pulse breakage of ores. Miner. Eng. 2015, 83, $168-174$. [CrossRef]

16. Hilden, M.M.; Powell, M.S. A geometrical texture model for multi-mineral liberation prediction. Miner. Eng. 2017, 111, 25-35. [CrossRef]

17. Napier-Munn, T.; Drinkwater, D.; Ballantyne, G. The CEEC Roadmap for Eco-Efficient Comminution. CEEC/JKTech Workshop on Eco-Efficient Comminution. CEEC the Future. Available online: https: //www.ceecthefuture.org/media/downloads/CEECRoadmap.pdf (accessed on 25 January 2020).

18. Delaney, G.W.; Morrison, R.D.; Sinnott, M.D.; Cummins, S.; Cleary, P.W. DEM modelling of non-spherical particle breakage and flow in an industrial scale cone crusher. Miner. Eng. 2015, 74, 112-122. [CrossRef] 
19. Johansson, M.; Quist, J.; Evertsson, M.; Hulthén, E. Cone crusher performance evaluation using DEM simulations and laboratory experiments for model validation. Miner. Eng. 2017, 103-104, 93-101. [CrossRef]

20. Tavares, L.M.; das Neves, P.B. Microstructure of quarry rocks and relationships to particle breakage and crushing. Int. J. Miner. Process. 2008, 87, 28-41. [CrossRef]

21. Weerasekara, N.S.; Powell, M.S.; Cleary, P.W.; Tavares, L.M.; Evertsson, M.; Morrison, R.D.; Quist, J.; Carvalho, R.M. The contribution of DEM to the science of comminution. Powder Technol. 2013, 248, 3-24. [CrossRef]

22. Klichowicz, M.; Frühwirt, T.; Lieberwirth, H. New experimental setup for the validation of DEM simulation of brittle crack propagation at grain size level. Miner. Eng. 2018, 128, 312-323. [CrossRef]

23. Klichowicz, M.; Lieberwirth, H. Modelling of Realistic Microstructures as Key Factor for Comminution Simulations. In Proceedings of the XXVIII International Mineral Processing Congress (IMPC), Québec, QC, Canada, 11-15 September 2016; pp. 1-10.

24. Kühnel, L. Untersuchungen zur Gutbettzerkleinerung in einer hydraulischen Stempelpresse; TU Bergakademie Freiberg: Freiberg, Germany, 2019. (In German)

25. Leißner, T.; Hoang, D.H.; Rudolph, M.; Heinig, T.; Bachmann, K.; Gutzmer, J.; Schubert, H.; Peuker, U.A. A mineral liberation study of grain boundary fracture based on measurements of the surface exposure after milling. Int. J. Miner. Process. 2016, 156, 3-13. [CrossRef]

26. Rahfeld, A.; Kleeberg, R.; Möckel, R.; Gutzmer, J. Quantitative mineralogical analysis of European Kupferschiefer ore. Miner. Eng. 2018, 115, 21-32. [CrossRef]

27. Evans, C.L.; Wightman, E.M.; Yuan, X. Quantifying mineral grain size distributions for process modelling using X-ray micro-tomography. Miner. Eng. 2015, 82, 78-83. [CrossRef]

28. Talovina, I.V.; Aleksandrova, T.N.; Popov, O.; Lieberwirth, H. Comparative analysis of rocks structural-textural characteristics studies by computer X-ray microtomography and quantitative microstructural analysis methods. Obogashchenie Rud 2017, 3, 56-62. [CrossRef]

29. Vaysberg, L.A.; Kameneva, E.E. Vozmozhnosti kompyuternoy mikrotomografii pri issledovanii fiziko-mekhanicheskikh svoystv gornykh porod (The possibilities of computer microtomography in the study of physical and mechanical properties of rocks). Gornyy zhurnal 2014, 9, 85-90.

30. Vaysberg, L.A.; Kameneva, E.E.; Pimenov, Y.G.; Sokolov, D.I. Issledovaniye struktury porovogo prostranstva granito- gneysa metodom rentgenovskoy tomografii. (The study of the structure of the pore space of granite-gneiss by x-ray tomography). Obogashcheniye Rud 2013, 3, 37-40.

31. Gasumov, R.A.; Gridin, V.A.; Kopchenkov, V.G.; Galai, B.F.; Dudaev, S.A. Research of Mining and Geological Conditions for Geological Exploration in Pre-Caucasus Region. Zapiski Gornogo instituta 2017, 228, 654-661. [CrossRef]

32. Ivanov, M.; Burlin, G.; Kalmykov, E. Petrophysic Research Methods of Core Material (Terrigenous Deposits); Book 1; Moscow University Publishing House: Moscow, Russia, 2008. (In Russian)

33. Shtyrlyaeva, A.A.; Zhuravlev, A.V.; Gerasimova, A.I. Prospects and problems of computer microtomography using for core samples studies. NGTP 2016, 11, 1. [CrossRef]

34. Willson, C.S.; Lu, N.; Likos, W.J. Quantification of Grain, Pore, and Fluid Microstructure of Unsaturated Sand from X-ray Computed Tomography Images. Geotech. Test. J. 2012, 35, 20120075. [CrossRef]

35. Ho, S.T.; Hutmacher, D.W. A comparison of micro CT with other techniques used in the characterization of scaffolds. Biomaterials 2006, 27, 1362-1376. [CrossRef] [PubMed]

36. Ditscherlein, R.; Leißner, T.; Peuker, U.A. Preparation techniques for micron-sized particulate samples in X-ray microtomography. Powder Technol. 2020, 360, 989-997. [CrossRef]

37. Leißner, T.; Diener, A.; Löwer, E.; Ditscherlein, R.; Krüger, K.; Kwade, A.; Peuker, U.A. 3D ex-situ and in-situ X-ray CT process studies in particle technology-A perspective. Adv. Powder Technol. 2019. [CrossRef]

38. Duryagina, A.; Talovina, I.; Shtyrlyaeva, A.; Popov, O.; Duryagina, A.; Talovina, I.; Shtyrlyaeva, A.; Popov, O. Application of Computer X-ray Microtomography for Study of Technological Properties of Rocks. Key Eng. Miner. 2018, 769, 220-226. [CrossRef] 
39. Glagolev, A.A. Quantitative analysis with the microscope by the point method. Eng. Min. J. 1934, 135, 339-400.

40. Unland, G.; Folgner, T. Automatische Kornformbestimmung durch photooptische Partikelanalyse. Die Naturstein-Industrie 1997, 5, 20-28. 